\title{
Food labels' impact assessment on consumer purchasing behavior in Malaysia
}

\begin{abstract}
The purpose of this study is to validate the impact of food labels among Malaysian consumers using an extended theory of planned behavior model (TPB). In doing so, the study assessed the direct and indirect effect of food labeling on consumer intention to purchase or otherwise the food products of interest. A stratified random sampling technique was adopted in selecting 2,014 consumers in Klang Valley, Malaysia. The results of structural equation modeling supported the adequacy of the proposed model. This study contributes to and extends the understanding of food labeling and purchasing behavior, identifying the rationales for purchasing of food products with labels that contains information such as halal logo, ingredients, and nutritive value.
\end{abstract}

Keyword: Attitude; Consumer; Food labeling; Purchasing behavior 